\title{
ESTRUCTURAS Y ENUNCIACIÓN EN LA NOVELA CORTA MODERNA
}

\author{
José Cardona-López \\ Texas A\&M International University \\ cardona@tamiu.edu
}

Resumen: Este artículo presenta y discute que en la novela corta moderna hay una estructura que es analógica en tanto que su enunciación narrativa es irónica, circunstancia que ocasiona una tensión entre ambos componentes del texto. En las novelas cortas modernas en las que se acude a lo epistolar, el diario y la fragmentación, la estructura analógica empieza a retraerse ante el aumento de la intensidad, aquella segunda parte del doble efecto estético que en esta forma literaria discutiera Judith Leibowitz. Con la presencia de la fragmentación, la estructura analógica acaba por ceder el paso al predominio de la enunciación narrativa irónica. De manera particular, para las novelas cortas modernas del siglo XX y lo que va del XXI la estructura fragmentaria que pueda haber en ellas corresponde también al diálogo de las letras con el desarrollo del mundo de la imagen representado, sobre todo, en la pintura y el cine, disciplinas artísticas tan precisamente dialogantes con el cubismo.

Palabras clave: estructura, enunciación, cartas, diario, fragmento.

\section{STRUCTURE AND ENUNCIATION IN THE MODERN SHORT NOVEL}

\begin{abstract}
This article presents and discusses that in the modern short novel there is an analogical structure while its narrative enunciation is ironic, a circumstance that causes a tension between these components of the text. In the modern novels in which the epistolary, the diary and the fragmentation are used, the analogical structure begins to retract before the intensity increases that second part of the double aesthetic effect that in this literary form Judith Leibowitz discussed. With the presence of fragmentation, the analogical structure will end up giving way to the predominance of ironic narrative enunciation. In particular, for the modern short novels of the $20^{\text {th }}$ century and so far in the $21^{\text {st }}$, the fragmentary structure that may exist in them also corresponds to the dialogue of the letters with the development of the world of represented image, especially in painting and cinema, artistic disciplines so precisely in dialogue with cubism.
\end{abstract}

Keywords: structure, enunciation, letters, diary, fragment.

DOI: $\underline{\text { https://doi.org/10.24029/lejana.2020.13.435 }}$

Recibido: el 2 de noviembre de 2018

Aceptado: el 1 de marzo de 2019

Publicado: el 19 de febrero de 2020 


\section{I}

En La clave de los campos (1936) de René Magritte hay dos planos. El que está al fondo muestra el paisaje de una colina y sus árboles, el otro es el compuesto por los pedazos del vidrio de la ventana que ahora caen y llevan consigo fragmentos de lo que se ve en el anterior. Estos fragmentos parecen representar aquellos que en la retina de la memoria se trae quien ha estado frente a una realidad, en este caso visual.

En razón de que en la pintura parece haber una intención de subrayar la captación de una realidad en forma fragmentada, el plano que corresponde a los trozos de vidrio equivaldría a una segunda capa de óleo puesta sobre la anterior y que además refuta ver la realiad como un todo casi inconsútil. Con esta lectura que hago, el plano del paisaje sería un palimpsesto a la vista que con su misma presencia más bien sugiere la necesidad de ver y contemplar la capa de óleo que lo cubre.

Para efectos de lo que quiero plantear y discutir, el plano del fondo de esta pintura es aquel que en una novela corta moderna fragmentaria es el todo que el lector debe recomponer a partir de una estructura que bien puede estar presentada como cartas, entradas de diario o solo fragmentos. Los fragmentos del primer plano serían la última capa de óleo del lienzo frente a la cual se encuentra el lector. ${ }^{1}$

\section{II}

Judith Leibowitz discute que en la novella o novela corta moderna hay una estructura repetitiva cuya función es contribuir al doble "efecto estético de la intensidad y la expansión simultáneas" (1974: 112). ${ }^{2}$ Para su argumentación ella parte de identificar un propio y específico punto de giro de la novela corta, que es diferente del Wendepunkt de Ludwig Tieck (Leibowitz, 1974: 79). El primero corresponde a la organización externa de la manera como se presenta la narración, el punto de giro central de Tieck a la historia que se narra.

Tanto el Wendepunkt y el punto de giro de la novela corta son expresiones de la confección del texto en manos del autor. De acuerdo con la Novellentheorie, la novela corta moderna debe su "eficacia y su poder de convencimiento [a] la severidad y lo artístico de su forma" (Bennett y Waidson, 1970: 18), características que al lector se transferirán en aquel doble efecto estético que plantea Leibowitz. Realización de la obra mediante la lectura, comparecencia del polo artístico y el estético que, de acuerdo con Wolfgang Iser, hay en una obra literaria (1972: 279).

Por su parte, John Gardner identifica tres posibles estructuras diferentes en la novela corta moderna. La primera corresponde a un fluir constante de la acción centrada en un solo personaje, que nutre su avance con momentos climáticos cada vez de mayor intensidad (Gardner, 2001: 218). Este tipo de estructura se encontraría en Luna caliente (1983) de Mempo Giardinelli. La segunda estructura es la de una narración que avanza con alternancias de focalización de varios personajes, con episodios que se presentan sin continuidad en el

\footnotetext{
${ }^{1}$ La novela corta moderna es una forma literaria breve que nace en y con los inicios de la modernidad, la que en Los hijos del limo Octavio Paz identifica entre finales del siglo XVIII y el XIX. De manera particular su nacimiento ocurre en brazos del romanticismo.

${ }^{2}$ Traducción mía. En las citas subsiguientes que provengan de textos escritos en un idioma diferente del español, todas las traducciones son de mi autoría.
} 
tiempo y las acciones (Gardner, 2001: 218). Crónica de una muerte anunciada (1981) de Gabriel García Márquez es un buen ejemplo del uso de este tipo de estructura. La estructura del "puntillismo ficticio" (Gardner, 2001: 218) es la tercera. La historia que se cuenta aparece en fragmentos, a veces como si estuvieran presentados de manera azarosa. Los momentos climáticos se logran no a la manera de una sucesión de eventos en forma lineal, presentados de manera seleccionada, sino con "la fuerza de la poesía" (Gardner, 2001: 219), la textura del lenguaje se torna lírica. Esta estructura se encuentra en Nueve veces el asombro (2005) de Alberto Ruy Sánchez.

\section{III}

A diferencia de la poesía, dice Federico Schlegel, en la novela corta lo subjetivo llega a tener una representación de manera indirecta, misma que "puede ser mucho más adecuada y elegante que la representación directa de la lírica, pues es exactamente lo que hay de indirecto y velado en esta forma narrativa lo que le presta un encanto superior" (2011: 86). Este planteamiento es similar a lo expuesto por Henry James respecto de ver la nouvelle como un cuadro que apunta a efectos ricamente resumidos y tratados en escorzo y que refieren sus términos de producción (1947: 139), también con los de Leibowitz sobre la novella como una narrativa eminentemente de la sugerencia (1974: 16). Escorzo, sugerencia y otras formas de expresión indirectas que están presentes en esta forma literaria corresponden a su brevedad, con lo que ella se ubicaría también en espacios propios de la poesía lírica, pero trasponiéndolos en beneficio de aquel "encanto superior" que plantea Schlegel.

En la nouvelle, según Pierre Tibi, se combinan simultáneamente lo narrativo de la novela con la brevedad del poema lírico (1995: 13). Prosigue en sus planteamientos y dice que "[a]l igual que el poema, finalmente la nouvelle puede establecer un humor, un estado de ánimo, una atmósfera en lugar de tratar de articular una historia” (1995: 14). Liliane Louvel señala que en procura de "decir lo indescriptible o lo inaudito, el nouvellista tiene que inventar su propio idioma, para hacerlo de una forma original, para constituir sistemas", entonces deberá echar mano de figuras retóricas y tropos que, más que en otras formas literarias, son necesarios para la economía expresiva de la nouvelle, y ya con su uso se "[g]anará en intensidad, en concentración, lo que se perdería en el desarrollo" (1995: 78). Los planteamientos de Tibi y de Louvel se basan de manera indistinta en el análisis de cuentos y novelas cortas, lo que corresponde a la imprecisión que desde hace un buen tiempo encierra el término nouvelle en el mundo académico y crítico de las letras francesas. No obstante, puesto que tales planteamientos se dan en el terreno de la narrativa breve, convienen también para utilizarlos en el análisis de una novela corta moderna.

Con lo señalado por Tibi y Louvel puede avanzarse aún más en la interpretación de lo que Leibowitz discute respecto de cómo en la novela corta moderna se logra el doble "efecto estético de la intensidad y la expansión simultáneas". Para que el texto lo alcance, el escritor se valdrá de la complejidad del tema y la estructura repetitiva, técnicas que permiten tratar implicaciones amplias relacionadas con el mismo tema, y éstas, a cambio de desarrollarse, más bien solo se sugieren (Cardona-López, 2003: 123). Si en la estructura repetitiva, tal como lo argumenta Leibowitz, se repiten motivos del tema principal y se exponen situaciones paralelas (17), ella sería analógica en tanto que su enunciación narrativa, en la que predomina 
un lenguaje propio de lo poético, sería irónica. Similar manifestación de contrarios habría también en el doble "efecto estético de la intensidad y la expansión simultáneas".

En razón de que en la novela corta moderna que acude a la estrutura fragmentaria la fragmentación sobre todo recae en el tiempo, ésta puede presentarse como cartas, entradas de diario o decididamente a fragmentos. Con la presencia de estas tres formas la estructura repetitiva que plantea Leibowitz, al igual que el carácter analógico de ella, empiezan a disiparse. De manera contraria la enunciación irónica se presenta aún con mayor fuerza gracias a la acentuación de una escritura en la que predominan las figuras retóricas y tropos que Tibi y Louvel encuentran de manera recurrente en la nouvelle, tales como sinécdoque, elipsis, paralipsis, antítesis, paradoja, oxímoron, litotes, quiasmo, metáfora y metonimia. A estos habría que agregar el símbolo, que en esta forma literaria es un tropo de presencia principal. Su importancia llega a ser tal que, como lo plantea la Falkentheorie, un objeto concreto y aún abstracto, de acuerdo con Werner Bergengruen (en Ahlers, 1974: 394), acaba por contener el significado de una novela corta moderna.

\section{IV}

Antes de proseguir quisiera hablar de Pensamientos de guerra (2000) de Orlando Mejía Rivera, obra que en 1998 mereció el Premio Nacional de Cultura de Colombia en la modalidad de novela. Esta nouvelle contiene las tres formas de fragmentación de las que voy a hablar. En cuanto a su destino en otros medios de expresión, al igual como ocurre con novelas cortas modernas, en 2001 tuvo una versión operística que se presentó con la Orquesta Sinfónica Juvenil de Colombia, el Taller de Ópera y el Grupo de Danzas de la Universidad de Caldas. En 2006 la obra fue adaptada al teatro, y como tal montada por el Departamento de Artes Escénicas de la Facultad de Artes Integradas de la Universidad del Valle.

En los capítulos llamados "La historia" aparecen recreaciones de algunas entradas de los Diarios Secretos de Wittgenstein y aún cartas que este envía a su amigo David. En unas y otras, el pensador habla desde el frente de batalla en que se encuentra durante la Primera Guerra Mundial, así como de la evolución de la escritura de su Tractatus. Esta novela corta moderna presenta también una narración que avanza en el tiempo de manera continua, es la que corresponde a los capítulos de "El prisionero". En ellos un narrador en tercera persona omnisciente refiere las jornadas que padece un profesor secuestrado por un grupo armado del que no se menciona su nombre. Como profesor tenía interés en escribir una biografía crítica de Wittgenstein, y con su memoria ya agujereada recuerda pasajes de su vida familiar y profesional. Estos capítulos están divididos en fragmentos. La combinación de una narración que da cuenta de las fatales condiciones del profesor en la selva y las de Wittgenstein en la guerra, configuran un texto en el que el lenguaje es puesto en cuestión. Al final el profesor, ya convertido en solo un esqueleto, se redime gracias al silencio, a la palabra que se agota.

\section{Querida Fulana de Tal: novela corta moderna epistolar}

Hacia la estructura fragmentaria de la novela corta moderna, en el siglo XVIII, el del esplendor de la novela epistolar, ella habría dado un paso importante con Las penas del joven Werther 
(1774) de Goethe. En esta novela corta aparecen cartas de Werther a su amigo Guillermo, destinatario que no le responde, y páginas que más bien son entradas de diario.

En lo epistolar, dice Claudio Guillén, "el Yo que escribe no solo actúa sobre el amigo, sino sobre sí mismo, viéndose desdoblado y objetivado sobre el papel, conforme las palabras y los conceptos se encadenan y suceden" (1990: 38). Este acto de confesión a dos bandas trasciende de lo privado a lo público gracias a la presencia del lector, a quien en el pacto de lectura de manera impúdica se le ha concedido un derecho de tercería. En uso de tal derecho, el lector hace lo suyo en un archivo muy ordenado, organizado por fechas. Desde luego, cuando la narración epistolar corresponde a la ficción expuesta en una novela o una novela corta moderna, y que es la que para nuestros propósitos corresponde, aquel pacto de lectura manifiesta sus luces en el terreno de lo estético, en el logro de la intensidad del efecto que señalara Baudelaire.

Una particularidad de la novela epistolar es la ausencia de narrador, como en un drama. Los personajes son los que refieren los acontecimientos que nutren la obra. En este caso, tal como lo plantea Guillén, hay ambigüedad y pluralidad de perspectivas (1990: 39). Esta característica es importante respecto de la novela corta moderna, pues conviene a su cercanía con el drama, lo que facilita que el texto pueda ser adaptado a las tablas y otras formas de expresión dramática, como el cine y aún el radioteatro. De manera particular, aunque no es una obra construida directamente como una novela corta epistolar, 84 Charing Cross Road (1970) de Helen Hanff ha pasado de la página impresa a espacios de la expresión actoral y dramática. Luego de estar en escenarios, la televisión y la radio, fue llevada al cine por David Hugh Jones con el título en español Nunca te vi, siempre te amé (1989). ${ }^{3}$

En las novelas epistolares, el tiempo es un cordel del que cuelgan espaciadamente las cartas, las que a la vez contienen su propio tiempo de lo que en cada una se narra. Kurt Spang sostiene que para el análisis del tiempo en una novela epistolar es muy útil distinguir "entre tiempo primario que sería el narrado en las cartas, [y] el secundario que comprendería el primario más los «huecos» producidos entre carta y carta" (2000: 649). Ya respecto de la estructura de este tipo de novelas, Spang plantea que en ellas las cartas son de carácter episódico y alcanzan coherencia entre sí por la otra historia, la principal, que se desarrolla en toda la narración (2000: 649). Es por esto que son "fragmentos de una historia total, pero también pueden tener una autonomía mayor guardando una independencia notable unas frente a otras" (Spang, 2000: 650).

En una novela corta moderna epistolar como Querido Diego, te abraza Quiela (1978) de Elena Poniatowska, en la que Quiela escribe cartas que no le responden, en ese tiempo secundario que identifica Spang, el lector puede asumir funciones como la de imaginar los blancos trascurridos entre las fechas de carta y carta, y hacer lo propio con las cartas que no escribe el destinatario. Sin dejar de ser lector puede volverse dos personajes a la vez, participar en la escritura del texto, tal como lo planteara Morelli en Rayuela (1962) de Julio Cortázar.

\footnotetext{
${ }^{3}$ Más tarde el libro inspiró la película china Finding Mr. Right (2013), dirigida por Xue Xiaolu. Fue tal su "éxito" de taquilla que en 2016 se lanzó Finding Mr. Right 2 (https://en.wikipedia.org/wiki/Finding_Mr._Right).
} 


\section{Querido diario: novela corta moderna en forma de diario}

Al igual que la carta en la novela epistolar, también el diario llega a ser una expresión de la ficción. La escritura en forma de diario, dice Hans Rudolf Picard, es "utilizada de un modo ficcional dentro de la estructura de la obra literaria" y de esta manera, "pasa a ser, de un modo completamente nuevo, comunicación estética" (1981: 119). La novela en forma de diario es un derivado de la epistolar. En la de diario, tal como dice Luis Beltrán Almería, la presencia del destinatario de las cartas o interlocutor se diluye, mientras la introspección aumenta (2011: 11).

En estas novelas el paso del tiempo lo señalan las fechas que marca cada entrada del diario, cartas que el Yo se escribe a sí mismo. Puede decirse que el verbo que define a estas novelas es el pronominal "ensimismarse", por lo que, en consecuencia, la carga de subjetividad en la narración es creciente. La intensidad que señala Leibowitz en la novela corta moderna está muy presente, pues cuando esta adopta la forma de diario suele haber un propósito de mostrar el desarrollo de un tema que se explora una y otra vez.

En La tregua (1960) de Mario Benedetti, el tema es "el tiempo psicológico, humano, vital", dice Eduardo Nogareda, tiempo que es "un gran vacío cubierto fugaz y fulgurantemente por la ráfaga vital del amor" (2014: 40). En esta novela corta ese tiempo que se explora y re-explora es el de la espera de la jubilación de Martín Santomé mientras él se da una tregua en ese mismo tiempo mediante el amor. En la mayor parte de La tregua, el paso del tiempo aparece registrado de manera continua, con fecha y día de la semana.

Frente a una novela corta moderna en forma de diario, el lector consuma un pacto de lectura similar al de la novela corta epistolar, pero ahora con una licencia para entrar a tiempos y espacios de lo muy privado vía la mediación de lo ficticio. Para usar palabras propias que convienen al tono dramático que tiene la nouvelle como forma literaria específica, en este caso la lectura parece darse a través del ojo de la chapa de la cuarta pared. A diferencia de la lectura de una novela corta moderna epistolar, ahora solo un personaje está a merced del lector, el Yo que se escribe a sí mismo es "asaltado" en su privacidad y rincones de su vida secreta por quien lee.

En su búsqueda literaria hacia un concepto nuevo de novela, Azorín va a echar mano del diario en Diario de un enfermo (1901). Para él, según Montserrat Escartín Gual, el uso de esta forma le facilitaba otras técnicas para "romper con la forma ortodoxa del relato decimonónico" (2002: 112). Al usar "un supuesto diario íntimo, con sus bloques desconectados en el tiempo" dice Escartín Gual, le "iba muy bien al autor para simbolizar tanto las piezas de un mundo que se derrumbaba, como una nueva manera de mirar más moderna y cinematográfica" (2002: 117).

En la novela corta moderna en forma de diario, del Yo que se escribe se muestran imágenes del movimiento suyo, de su estar en la vida y el mundo y, al igual que en el cine, hay fragmentación y morosidad en el paso del tiempo. En Cuando ya no importe (1993) de Juan Carlos Onetti, el diario de John Carr, intelectual de medianía, registra la permanencia de él en Santamaría, adonde ha ido a trabajar con una falsa identidad y luego deberá enterarse de que sus labores sirven para encubrir otras de un grupo de contrabandistas. El tiempo transcurre muy fragmentado, no a la manera de fotogramas del día a día como sucede en $L a$ náusea (1938) de Jean-Paul Sartre o en casi toda La tregua, sino en una especie de montaje o 
edición en el que ha primado la necesidad de mostrar solo lo esencial de la vida de Carr viviendo una situación.

El diario como forma fragmentada de una novela o una novela corta moderna da oportunidad a que el ensayo encuentre espacio, a lo que contribuye la autonomía de los fragmentos de tiempo que en ella se exhiben. El Yo privado se afirma desde el campo de las ideas y el tono del ensayo que llega a aparecer suele ser intimista, confesional, a la manera de Montaigne. Este es el caso de De sobremesa (1925) de José Asunción Silva, la que el autor reescribió luego de que en 1895 perdiera el manuscrito en el naufragio del barco en que regresaba de Venezuela a Colombia. Juan Loveluck llama a esta obra "novela-ensayo" y dice que en ella se presenta "una asistemática teoría del hombre finisecular y de sus conflictos básicos" (1965: 25).

\section{Querido lector: novela corta moderna en forma de fragmentos}

Según Maurice Blanchot, la escritura fragmentaria es "una forma discontinua [que] se adapta a la ironía romántica puesto que por sí sola puede disponer la coincidencia del discurso y el silencio, de lo lúdico y lo serio, de lo declarativo imperioso — verdaderamente oracular- y la indecisión del pensamiento inestable y dividido" (1983: 171). Frente al fragmento que en Federico Schlegel acaba por ser aforismo, unidad completa y cerrada, ${ }^{4}$ Blanchot dice que hay uno especial que no se concentra en sí mismo y va unido a otros, que en la escritura fragmentaria se atiene a la estructura rítmica de espera y pausa, y que no es una forma de escribir que tienda a dificultar la visión de conjunto a pesar de que llegue a superar la totalidad (1983: 172). La escritura fragmentaria sería una que desde el mismo lienzo del todo a este lo acecha, alude y contiene a medida que avanza en aquella estructura rítmica. Con este desempeño, tal tipo de escritura muestra un desmonte del todo para luego dar acceso a él de otra manera, con una visión más múltiple y abierta en significados.

Lo planteado por Blanchot encuentra legitimidad en el desarrollo de otros espacios de las artes. La pintura deberá esperar siglos para que el punto de fuga de Alberti, Mategna y Massacio sea cuestionado con los planteamientos del cubismo. Por su parte, de manera temprana el cine aparece conllevando en sus entrañas la posibilidad de narrar como lo establece D. W. Griffith basado en la novela decimonónica o de mostrar imágenes a lo Dziga Vértov, organizadas en un orden de intención poética.

La sintaxis con que se expresa el cine es simultánea, contraria a la literaria que es sucesiva. Sea un cine que narre o muestre, mediante fragmentos, secuencias, planos, encuadres y todas las diversas posibilidades que tiene para presentar el tiempo, finalmente se construye una historia. El lenguaje fílmico suele acudir a la asociación de imágenes bien sea por afinidad, semejanza, desemejanza u otra opción, y de este lenguaje el escritor puede tomar lo que le convenga para sus fines creativos. Siguiendo las razones del cine, y aún las del cubismo, pudiera decirse que en la novela fragmentada su enunciación la brinda un ojo que escribe, de ahí la importancia que en estas novelas adquiere la imagen. En una novela corta moderna de estructura decidiamente fragmentaria, por lo general, cada fragmento gravita

\footnotetext{
${ }^{4}$ El fragmento 206 de F. Schlegel dice: "Como una pequeña obra de arte, un fragmento debe estar aislado del mundo que lo rodea y ser, en sí mismo, perfecto y acabado como un erizo" (2009: 105).
} 
alrededor de una imagen, la que viene a ser su centro. Esto lo vemos en La última niebla (1935) de María Luisa Bombal. En Los adioses (1954) de Onetti, aquel "ojo que escribe" empieza literalmente narrando desde un principio: "Quisiera no haber visto del hombre, la primera vez que entró en el almacen, nada más que las manos" (9). Más adelante, en el curso de la narración, algunos personajes cobran presencia gracias al recurso de la fragmentación metonímica que otorga la mirada del almacenero sobre ellos. ${ }^{5}$

La novela corta moderna en forma de fragmentos se asemeja a los cuadernos de notas de los escritores. En ellos es frecuente hallar una conjunción de pensamiento y literatura, aunque los textos que van a ser de orden literario solo aparezcan como proyectos. Esto puede verse en los Carnets (1966) de Albert Camus o en el Cuaderno (1987) de Anton Chéjov. Ya en el nivel de solo el pensamiento, y haciendo a un lado las secciones epigramáticas, destacan El ocaso de los ídolos (o cómo se filosofa a martillazos) (1984) de Fiedrich Nietzsche y Breviario de podredumbre (1983) de E. M. Cioran. En estos dos últimos libros, la filosofía es un ejercicio de estilo, y también lo contrario.

En la nouvelle en forma de fragmentos que corresponde a la del puntillismo ficticio que identifica Gardner, el Yo que escribe acaba por manifestarse como un hablante lírico. Frente a ese Yo, el del que lee interviene en forma abundante. A veces esa intervención del Yo ajeno al texto se tiraniza porque el lector llega a leer el fragmento que desea o le atrajo, hace saltos grandes entre los blancos de fragmento y fragmento. Pareciera que el Yo que está en la obra se hiciera a un lado ante la fuerza y actitud del lector.

Pero en la novela en forma de fragmentos y en la novela corta moderna que adopta esta estructura no solamente hay una voz en primera persona, también comparece la de un narrador en tercera persona en todas sus variantes. El tiempo medido en fechas en cartas y entradas de diario desaparece y da lugar a esa otra voz narrativa, lo que va a permitir que diversos tiempos y espacios comparezcan creativamente al amparo de otras perspectivas narrativas.

\section{V}

Respecto del tiempo de lectura de una novela corta moderna epistolar, en forma de diario o solo fragmentos, de nuevo el lector lo consume de contado, a diferencia de como lo hace ante una novela, que es a plazos. En ese tiempo breve ante el lector se presentan personajes en acción, personajes comprometidos en el escenario propio de la nouvelle, la que, como plantea Herman Broch, "no da una totalidad de la vida sino una totalidad de la situación" (citado por Bennet y Waidson, 1970: 260).

Puede hablarse de una estructura del proceso de lectura de una novela corta moderna fragmentaria, y para hacerlo quisiera regresar a La clave de los campos. En esta pintura hay una realidad mostrada a dos planos, con uno superpuesto al otro, a ese palimpsesto a la vista del que hablé al principio. De manera análoga ante una novela corta moderna fragmentaria, el

\footnotetext{
${ }^{5}$ No obstante, los diversos caminos literarios que favorecen el cubismo y el cine, hay que recordar que el fragmento también tiene su genealogía en el Romanticismo. Los hermanos Schlegel, Novalis y Ludwig Tieck, todos miembros del Círculo de Jena, aparecen entre los pioneros en el uso del fragmento y sus compromisos con destinos literarios. Ellos crean Athenaeum (1798-1800), revista que fuera espacio para el pensamiento filosófico mediante la escritura colectiva y fragmentaria.
} 
lector tendría una última capa de óleo para leer, similar a la que muestra lo que yo identifico como el primer plano del cuadro de Magritte.

Cartas, entradas de diario y fragmentos, en su enunciación narrativa contienen el tiempo de lo que en en ellos sucede o se muestra. Unir piezas de tiempo, llenar los blancos entre unas y otros, es labor del lector. Esta es una operación de lectura de lo eludido y aludido, de la sugerencia, que ocurriría en un eje horizontal y que yo llamo estructura de lectura de primer grado. Durante el tiempo breve de lectura que insume una novela corta, mientras la obra va logrando la intensidad del efecto de Baudelaire, el lector poco a poco se apodera de fragmentos que asocia, ata, cose entre sí, para acceder a una lectura de segundo grado, que es aquella donde se sitúa la totalidad de la realidad, el palimpsesto. El lector restablece, pues, la primera capa de óleo, la que viene a ser aquella "Gestalt" o totalidad organizada que se percibe más que como si fuera solo la suma de sus partes y que Iser menciona al hablar de "[1]a «imagen» que realiza nuestra imaginación mediante el paso a paso del proceso de lectura" (1972: 288). El lector tiene acceso a esa totalidad gracias a que puede "ver" y abarcar todo el palimpsesto, el texto ausente donde el tiempo y las acciones fluyen de manera constante e ininterrumpida, pero que también es un texto que el autor se negó a escribir. Y, hay que decirlo, el lector alcanza aquel palimpsesto conduciéndose entre los espacios del misterio y la extrañeza de un lenguaje que privilegia lo poético.

Para alcanzar la lectura de segundo grado, esa donde se sitúa la totalidad, el lector parece moverse en un eje similar al de la cámara de cine en una toma de profundidad de campo. Siendo así, los pasos de esta acción muestran una operación de lectura similar a la de un romance. En cada cuarteta ocurre o se presenta algo mediante los versos que corren de manera horizontal y sujetos a la métrica octasilábica. Y poco a poco, frente a un lenguaje que se vale de alusiones y elusiones, el lector va logrando acceso a la totalidad de lo que se refiere en el romance.

La estructura de la lectura que acabo de señalar contendría los momentos en que la novela corta moderna fragmentaria como artefacto artístico va a lograr el doble efecto estético de intensidad y expansión simultáneas que plantea Leibowitz. Cuando la narración está presentada en fragmentos que ya no son cartas ni entradas de diario, puede verse que la estructura analógica del texto se ha disipado, si no desaparecido. Por su parte, la enunciación irónica de la narración se ha manifestado en forma abundante, gracias a la troponimia y figuras retóricas tan propias de la manera de expresarse que el nouvellista ha inventado con el fin de "decir lo indescriptible o lo inaudito" (Louvel, 1995: 78). Flores (2005) de Mario Bellatin es una novela corta moderna construida a base de fragmentos. Incluso, al principio de ella, el autor declara la arquitectura y el sentido de lo que será la obra, pues habla de "una antigua técnica sumeria [...] que permite la construcción de complicadas estructuras narrativas basándose en la suma de determinados objetos que juntos conforman un todo" (2005: 377). En Cuando ya no importe de Onetti las entradas del diario de Carr están muy distanciadas en fechas, lo que además se acentúa por grandes espacios en blanco entre ellas, totalmente opuesto a como aparecen las de La tregua de Benedetti. El principio del placer (1997) de José Emilio Pacheco también privilegia la forma del diario, pero sin marcar las entradas por fechas, aunque dejando espacios en blanco de buena amplitud. 


\section{VI}

A partir de lo expuesto quisiera plantear algunas conclusiones.

La novela corta moderna a fragmentos es el resultado de una especie de destilación de la epistolar, de una separación de sus componentes. En la primera condensación, ha desaparecido el otro como destinatario, queda el paso del tiempo marcado por las fechas en las entradas del diario y el Yo se escribe a sí mismo. Ya en la siguiente condensación, se encuentra la nouvelle de estructura decididamente fragmentaria.

En la novela corta moderna epistolar, de diario y la decididamente fragmentada, la estructura repetitiva que plantea y discute Leibowitz, que es analógica, cede ante una enunciación narrativa irónica, misma cuya capacidad expresiva se ve acentuada por una escritura subjetiva en las que predominan figuras retóricas y tropos. Tal enunciación principalmente es de orden poético.

Debido a que en la nouvelle a fragmentos la realidad narrativa ha explosionado en diversos pedazos, aparecen otras voces diferentes de la primera persona de la epistorlar y la de forma de diario. El espejo ha estallado, también las diversas voces que se anudan en la polifonía silenciosa del Yo. La voz más frecuente suele ser la tercera omnisciente en todas sus posibles variantes.

La lectura de una novela corta moderna fragmentaria cubre dos planos, el de las cartas, entradas de diarios o solo fragmentos, y aquel de un palimpsesto que equivale a un texto ausente y que contiene una totalidad organizada que es mayor que la sola suma de sus partes. En el plano de la fragmentación se da una lectura de primer grado, en el otro, una de segundo grado.

\section{Bibliografía}

AHLERS, Hans Peter (1974): “Werner Bergengruen's Metaphysics of the Novelle". Monatshefte 66 (4) (1974): 387-400.

BELTRÁN ALMERÍA, Luis (2011): "Novela y diario”. En Luisa Paz Rodríguez Suárez y David Pérez Chico (eds.), El diario como forma de escritura y pensamiento en el mundo contemporáneo. Zaragoza, Institución Fernando el Católico: 9-19.

BELLATIN, Mario (2005): Obra reunida. México, Alfaguara.

BENNETT, E. K. y H. M. WAIDSON (1970): A History of the German Novelle. London, Cambridge University Press.

BLANCHOT, Maurice (1983): “The Athenaeum”. Trads. Deborah Esch y Ian Balfour. Studies in Romanticism 22 (2) (1983): 163-172. DOI: https://doi.org/10.2307/25600425

CARDONA-LÓPEZ, José (1983): Teoría y práctica de la nouvelle. Ciudad Juárez, Universidad Autónoma de Ciudad Juárez.

ESCARTÍN GUAL, Monserrat (2002): "El diario íntimo, Azorín y la nueva novela". Revista $\begin{array}{lllll}\text { de Literatura (2002): } & \text { LXIV7-120. }\end{array}$ https://doi.org/10.3989/revliteratura.2002.v64.i127.192

GARDNER, John (2001): El arte de la ficción. Trad. Miguel Martínez-Lage. Madrid, Ediciones y Talleres de Escritura Creativa Fuentetaja. 
GUILLÉN, Claudio (1990): “Correspondencia epistolar y literatura”. Boletín Informativo 211 (1990): 35-39.

ISER, Wolfgang (1972): "The Reading Process: A Phenomenological Approach". New Literary History 3 (2) (1972): 279-299. DOI: https://doi.org/10.2307/468316

JAMES, Henry (1947): The Art of the Novel. Critical Prefaces. Ed. Richard P. Blackmur. Nueva York, Charles Scribner's Sons.

LEIBOWITZ, Judith (1974): Narrative Purpose in the Novella. París, Mouton. DOI: https://doi.org/10.1515/9783110883565

LOUVEL, Liliane (1995): "Figurer la nouvelle: Notes pour un genre pressé". En Paul Carmignani (ed.), Aspects de la nouvelle (II). Perpignan, Presses Universitaires de Perpignan: 77-122.

LOVELUCK, Juan (1965): "De sobremesa, novela desconocida del modernismo". Revista $\begin{array}{lllll}\text { Iberoamericana } & 31 & (59) & \text { (1965): }\end{array}$ https://doi.org/10.5195/reviberoamer.1965.2173

NOGAREDA, Eduardo (2014): "Introducción”. En Mario Benedetti, La tregua. Ed. Ricardo Nogareda. Madrid, Cátedra: 9-57.

ONETTI, Juan Carlos (1993): Cuando ya no importe. Madrid, Alfaguara.

--- (2007): Los adioses. Madrid, Punto de Lectura.

PICARD, Hans Rudlof (1981): “El diario como género entre lo íntimo y lo público". 1616: Anuario de la Sociedad Española de Literatrua General y Comparada, vol. 4 (1981): 115-122.

SCHLEGEL, Friedrich (2009): Fragmentos. Trad. Pere Jaredols. Barcelona, Marbot Ediciones.

--- (2011): “Relato sobre as obras poéticas de Giovanni Boccaccio". En Constantino Luz de Medeiros, "Friedrich Schlegel: Relato sobre as obras poéticas de Giovanni Boccaccio. Tradução e estudo preliminar". Tesis doctoral inédita. Universidade de São Paulo: 6689. DOI: https://doi.org/10.11606/d.8.2011.tde-26032012-105715

SPANG, Kurt (2000): "La novela epistolar. Un intento de definición genérica”. Rilce 16 (3) (2000): 639-656.

TIBI, Pierre: (1995): “Essai de compréhension d'un genre”. En Paul Carmignani (ed.), Aspects de la nouvelle (II). Perpignan, Presses Universitaires de Perpignan. 9-76.

(C) José Cardona-López

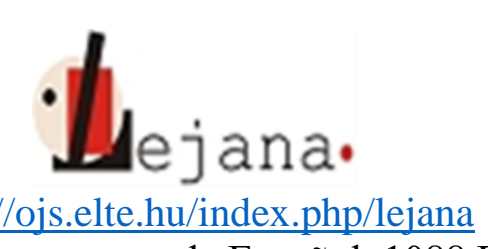

Universidad Eötvös Loránd, Departamento de Español, 1088 Budapest, Múzeum krt. 4/C 